\title{
Pushing the sensitivity limits of RTS-based continuous deformation monitoring of an alpine valley
}

\author{
Mariusz Frukacz $^{1}$ (D) $\cdot$ Robert Presl $^{1} \cdot$ Andreas Wieser $^{1} \cdot$ Daniele Favot $^{2}$
}

Received: 8 July 2016 / Accepted: 9 January 2017 / Published online: 21 January 2017

(C) The Author(s) 2017. This article is published with open access at Springerlink.com

\begin{abstract}
Monitoring applications may require operating robotic total stations (RTS) at the limit of their sensitivity with respect to target displacements. Thorough understanding and mitigation of systematic effects are required in order to reach or push this limit. We investigate some of these effects, in particular effects external to the total station, using data and experience gained from a continuously operating monitoring system installed at the terminus of the Great Aletsch Glacier in Switzerland. The system consists of two robotic total stations, about 60 prisms, four global navigation satellite system (GNSS) receivers, thermocouples, inclinometers, and meteo-sensors. The purpose of the monitoring is to study reversible deformations of the adjacent slopes, likely driven by snowmelt and mountain water level changes. The deformations reach the millimeter- to centimeter-level and shall be studied on time scales ranging from annual to sub-annual, and ideally even down to daily or sub-daily resolution. Our investigation focuses on four aspects: protective housing, pillar stability, refraction, and stability of orientation, all of which were found to affect the measurements on the milligonlevel with lines-of-sight of up to $2 \mathrm{~km}$. The results highlight signatures of apparent point displacements, and the discussion comprises approaches to bounding
\end{abstract}

This paper is a revised version of the paper presented at JISDM 2016.

Mariusz Frukacz

mariusz.frukacz@geod.baug.ethz.ch

1 Institute of Geodesy and Photogrammetry (IGP), ETH Zürich, Stefano-Franscini-Platz 5, 8093 Zürich, Switzerland

2 Terradata AG, Mühlestrasse 9, 8840 Einsiedeln, Switzerland or mitigating these effects which may also be expected in similar monitoring situations at other locations.

Keywords Robotic total station · Geodetic monitoring · Systematic effects $\cdot$ Refraction $\cdot$ Orientation

\section{Introduction}

Robotic total stations (RTS) are routinely used for geodetic monitoring if high accuracy (millimeter-level or better) is required and the object or area of interest can be represented by a set of marked and possibly stabilized points with line-of-sight (LoS) visibility from a sufficiently low number of specially selected instrument sites. Examples of such systems can be found for example in monitoring of tunnels (Kaalberg et al. 2003), landslides (Stiros et al. 2004), rockfalls (Loew et al. 2012), and man-made structures (Papastamos et al. 2015, Soni et al. 2015). Even with potential alternatives like global navigation satellite system (GNSS) (Crosta and Agliardi 2003), image-assisted total stations (Charalampos et al. 2015), laser scanners (Gigli et al. 2014), ground-based radars (Caduff et al. 2015), or photogrammetric systems (Di Crescenzo and Santo 2007), total stations may be the best-or sometimes even the only-option in terms of sufficient sensitivity (including proper modelling and handling of uncertainties), clear interpretation of the monitoring results (in particular if the monitored points are unambiguously represented by prisms), safety, economic feasibility, and possibly further aspects. Sometimes, total stations need to be operated close to or even beyond the limit of their capabilities as specified by the manufacturer in order to meet the demands of an application. An example is the 
monitoring system installed and gradually extended for studying short- and long-term deformations on the millimeter- to centimeter-level of the valley along the terminus of the Great Aletsch Glacier in Switzerland. ${ }^{1}$

Data from two permanent GNSS stations installed in 2012 had shown annual patterns of rapid narrowing of the valley in spring and slow widening during autumn and winter with a peak-to-peak displacement of about $2 \mathrm{~cm}$. This deformation is likely driven by snowmelt and groundwater-table changes. The geodetic monitoring system used herein was installed to further investigate the factors controlling reversible and irreversible slope displacements and deformations in the paraglacial environment of this glacier (Glueer et al. 2015).

The system now consists of two robotic total stations each observing about 30 prisms several times per day and night, four GNSS receivers/antennas continuously collecting measurements at a 30-s data rate, meteo-sensors located next to the RTS, and rock temperature sensors (see Fig. 1). One total station (RTS1) is a TCRP1201 installed in 2013 at about $1949 \mathrm{~m}$ a.s.l. (LoS at least $50 \mathrm{~m}$ above the ice, distance to prisms 42 to $1751 \mathrm{~m}$, see Fig. 2); the other one (RTS2) is a TM50 installed in 2014 at about $2173 \mathrm{~m}$ a.s.l. (LoS at least $400 \mathrm{~m}$ above the ice, distance to prisms 127 to $2045 \mathrm{~m}$ ). Both total stations were installed on pillars (see the "Pillar stability" section), are remotely operated via GSM/UMTS from a server at ETH Zürich running GeoMoS, and are powered by solar panels and backup batteries. Two of the GNSS antennas are collocated with the RTS, each of them mounted concentrically (but not rotating) directly above the respective total station. The pillar and supporting rock of RTS2 have been equipped with additional sensors for the stability investigations shown in the "Pillar stability" section.

The majority of prisms are installed on profiles along the dip direction of the slopes. They are mounted directly on compact rock (gneiss and granite). The other prisms are installed in landslide areas where displacements of about $10 \mathrm{~cm}$ per year along the dip direction were expected. Unfortunately, no stable areas for placing reference points were available or known beforehand. The total stations were installed in areas assumed to be stable except for the previously mentioned widening and narrowing of the valley.

The measured angles and distances as retrieved from the GeoMoS database (mean of dual-face measurements) vary within ranges of 4-6 mgon and 4-6 mm, respectively. Figure 3 shows this for RTS1 and selected target points during 1 month in late summer 2015. We assume that most of these patterns are due to systematic deviations, not to actual displacements of the monitored points.

\footnotetext{
${ }^{1}$ The system was installed and is operated by the Geological Institute, ETH, Engineering Geology group, with support from BSF Swissphoto and from the authors of this paper.
}

The angular variations reach about five to ten times the standard deviation specified by the manufacturer; the distance variations are on the level of the specified standard deviations. However, the raw observations are correlated both in space and time, as can be seen from the figure. The common daily patterns of the horizontal angles (Fig. 3, top) suggest residual orientation changes not properly accounted for during data acquisition. The largest vertical angle variations are observed for point 18 with the LoS along the valley (Fig. 2, bottom) and are likely caused by vertical refraction. The apparently systematic distance variations are likely due to residual meteorological effects (they are greatest for points at long distances measured across the valley, like 4 and 14 in Fig. 3) and possibly also to instabilities of the pillar or its support.

We will subsequently address four aspects which limit or negatively affect the accuracy of the displacements extracted from the RTS measurements, namely the protective housing, pillar stability, refraction, and total station orientation.

\section{Protective housing}

The total stations were set up in remote locations, hardly accessible during the winter months, exposed to direct sunlight, harsh alpine weather conditions, potentially to animals, and easily reachable by hikers and mountaineers passing by during the summer months. So, it was decided to protect the instruments in excess of their weatherproof design (International Protection Marking IP54 and IP65, respectively) by an additional protection box consisting of plane acrylic windows and four posts (see Fig. 4).

For a system maintenance, the housing had to be removed and was then put back into place. The previous orientation and position relative to the total station were reproduced within the little slackness of the mounting screws and holes. The time series of horizontal angles of some points jumped by up to 20 mgon after this maintenance while most targets seemed not to be affected. These changes, corresponding to apparent sudden lateral displacements of some monitored points by $20 \mathrm{~cm}$, were clearly non-negligible artifacts caused by the protective housing but not explainable by a tilt of the acrylic windows according to the effects of a plane parallel plate.

An exact replica of the housing and a suitable experimental setup in the geodetic metrology laboratory of IGP (Fig. 5) were used to investigate the effect of the housing on the total station measurements. In particular, measurements to a fixed prism about $50 \mathrm{~m}$ from the total station were made and recorded while the protective housing was rotated stepwise about its vertical axis, collinear with the total station's vertical axis. For comparison, the process was repeated with the acrylic panes removed from the housing, and subsequently also with different total stations. 
Fig. 1 The monitoring points at the Great Aletsch Glacier and two selected profiles (dashed red lines) later discussed in this paper (background image (C) 2015 swisstopo, JD100042)

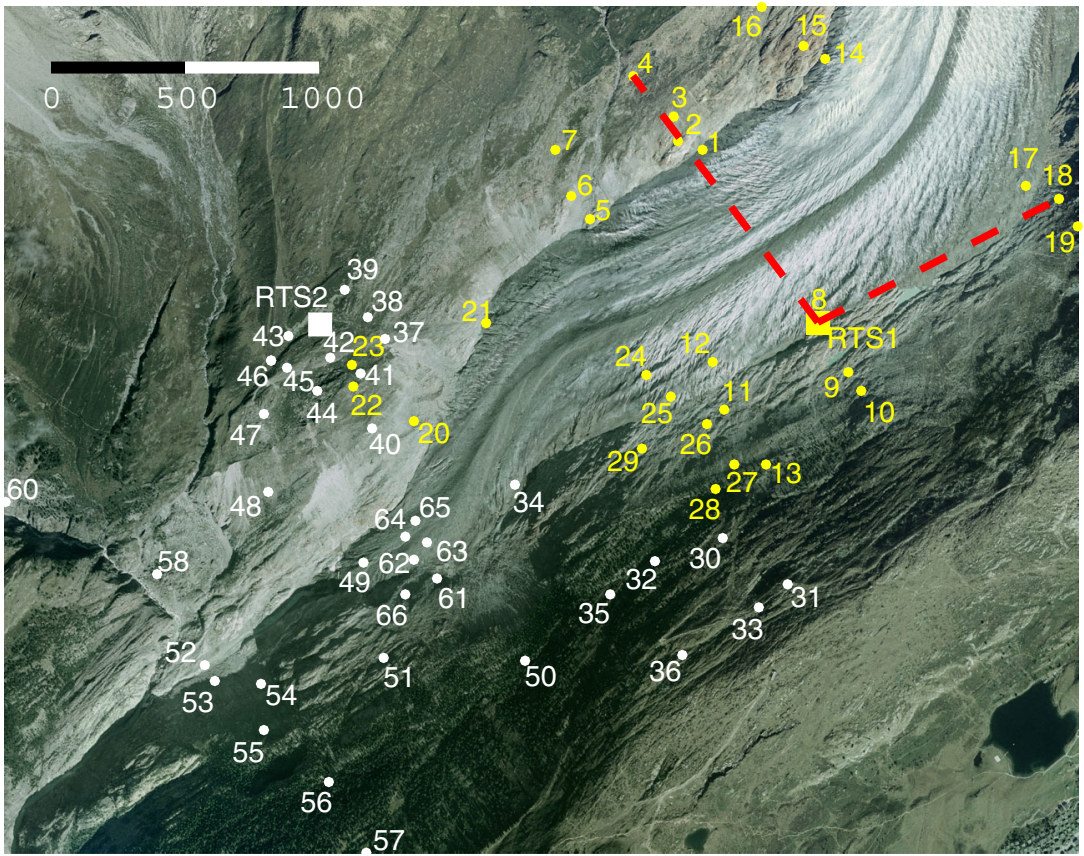

Figure 6 shows the variations of the measurements obtained during one such experiment. The blue lines correspond to the TCRP1201 measurements without acrylic windows (but with the frame and posts of the protective box still in place). The measurements are mostly constant apart from random noise well within the specification of the instrument. However, the horizontal angles are heavily and systematically affected when the box is rotated by about 45 gon either way from the LoS to the prism. The reason is obstruction of the prism (target) by the posts. The automatic target recognition algorithm does not detect (and flag) the problem until the obstruction exceeds a certain limit. In this test, the corresponding error, not detectable from the total station output alone, reaches about 6 mgon. The distance and vertical angle

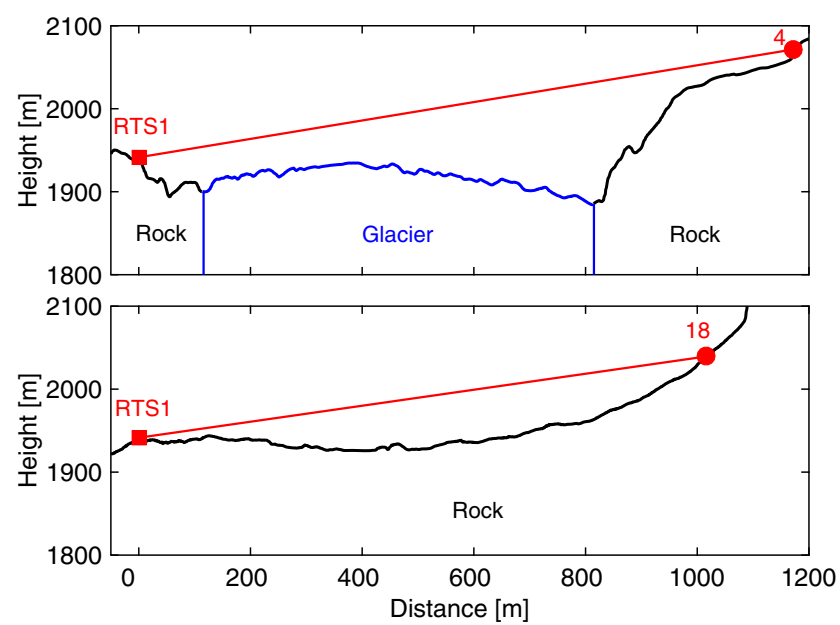

Fig. 2 Two selected profiles along LoS from RTS1 to point 4 (across the valley) and point 18 (along the valley) measurements are not affected by the partial obstruction, as may be expected since the posts are vertical.

With the acrylic windows inserted, the measurements are systematically affected, in particular the distances and horizontal angles. All three instruments (TCRP1201, MS50, and S8) show a very similar behavior except for certain effects close to the region where the LoS is approximately perpendicular to the window surface. There, the S8 does not output measurements within a cone of about \pm 3 gon, while the target recognition of the MS50 is still active, but produces outliers of horizontal and vertical angles within a region of about \pm 0.5 gon. The measurements of the TCRP1201 mainly exhibit higher noise in the immediate vicinity of the window's surface

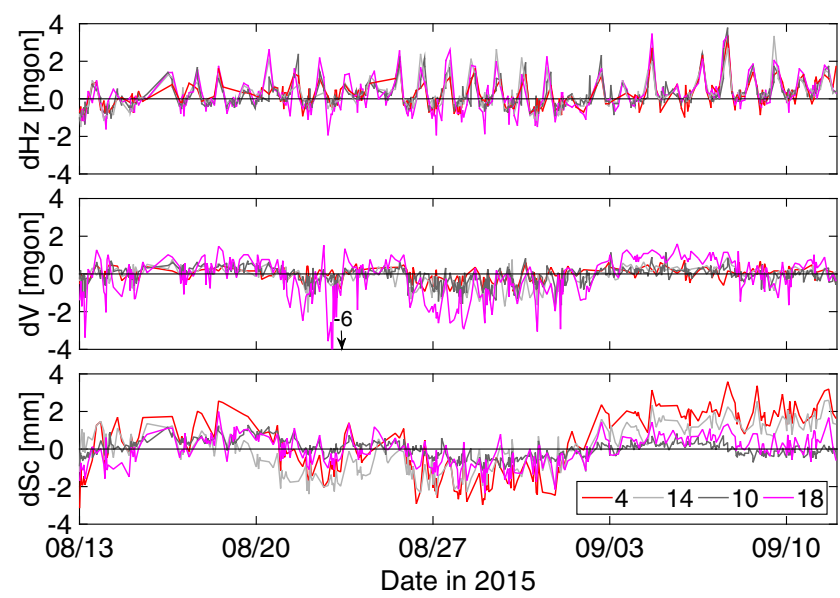

Fig. 3 Variations of horizontal and vertical angles as well as slope distances (after standard atmospheric correction) for selected points measured by RTS1 calculated with respect to the median value of the selected time period 
Fig. 4 RTS1 on its pillar with initial protective housing in place (picture: Geological Institute, ETH Zürich)

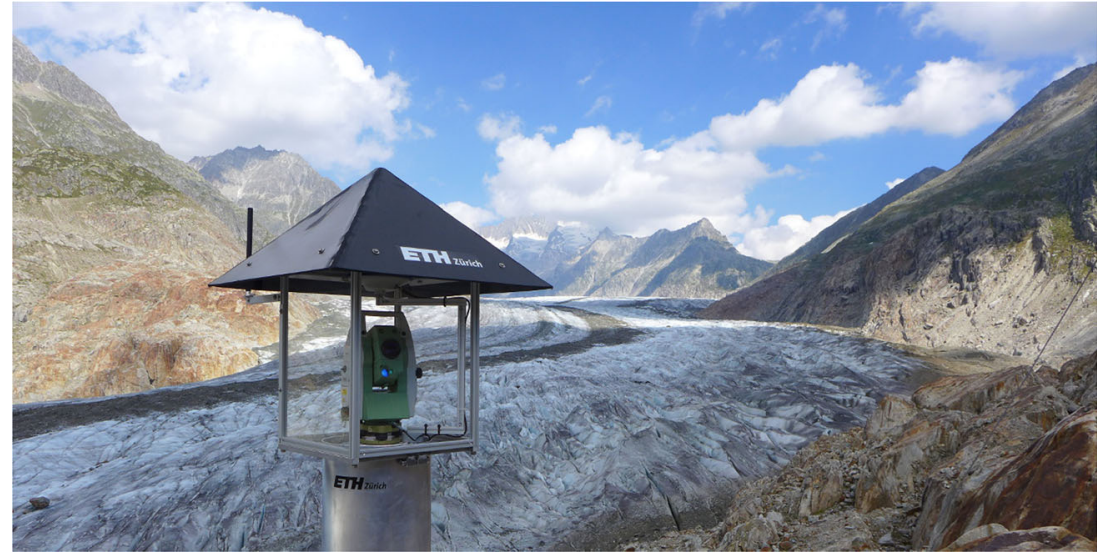

normal. ${ }^{2}$ The offset and non-linearity of the distance variations (Fig. 6, bottom) are fully explained by the thickness, refractive index, and varying rotation angle of the window. The asymmetry and non-linearity of the horizontal angle variations and the fact that they are nowhere 0 indicate that the acrylic window is not plane parallel. We could reproduce the error pattern numerically by assuming that the window is slightly wedge-shaped. Non-parallelism of only a few hundredth of a millimeter was enough to explain the effect that we had found.

The increased deviations towards both ends of the curve are caused again by the posts. The smaller scale variations differing between the instruments persisted with independent repetition of the experiment and are most likely due to local inhomogeneities of the windows both in terms of geometry and refractive index which affect the instruments differently because of the different target recognition technology (including effective spatial low-pass filtering by the finite diameters of the optical beams).

The reason for the jump of the measurements of RTS1 after the maintenance was thus due to partial obstruction of LoS by the posts. However, the lab investigation showed that an additional housing may critically impair the monitoring system even if such obstructions are avoided. The horizontal angle errors change with changing angle between LoS and window surface by up to $0.4 \times 10^{-3} \mathrm{mgon} / \mathrm{mgon}$ (except in the immediate vicinity of the posts, where they are higher). While this may be uncritical for many monitoring applications, it may result in significant errors of the estimated displacements if the window is replaced, if its orientation changes because of external influences or work, or if a target point moves by more than about 0.5 gon $(0.8 \mathrm{~m}$ at a distance of $100 \mathrm{~m})$.

\footnotetext{
${ }^{2}$ These situations can of course be avoided in a real-world monitoring application by tilting the respective window sufficiently w.r.t. LoS, and in fact, practitioners have known this for a long time.
}

We found qualitatively similar results with high-quality glass instead of acrylic and significantly worse results with an acrylic cylinder instead of the planar windows. Ideally, if an additional protection is required at all, the measurements should be made through sufficiently big holes in the housing rather than through any kind of transparent material. We have also investigated this using an experimental setup like before and found that the diameter of the holes should be larger than the aperture of the telescope to avoid systematic errors on the level of milligons to tens of milligons caused by partial obstruction or distortion of the measurement beams when they touch or overlap the border of the holes. For the total stations mentioned above, we found that holes of at least $50 \mathrm{~mm}$ diameter should be drilled at the required locations to account for instrument beam width, for potential target point displacements, and for limited precision of the hole's location w.r.t. the total station once the entire

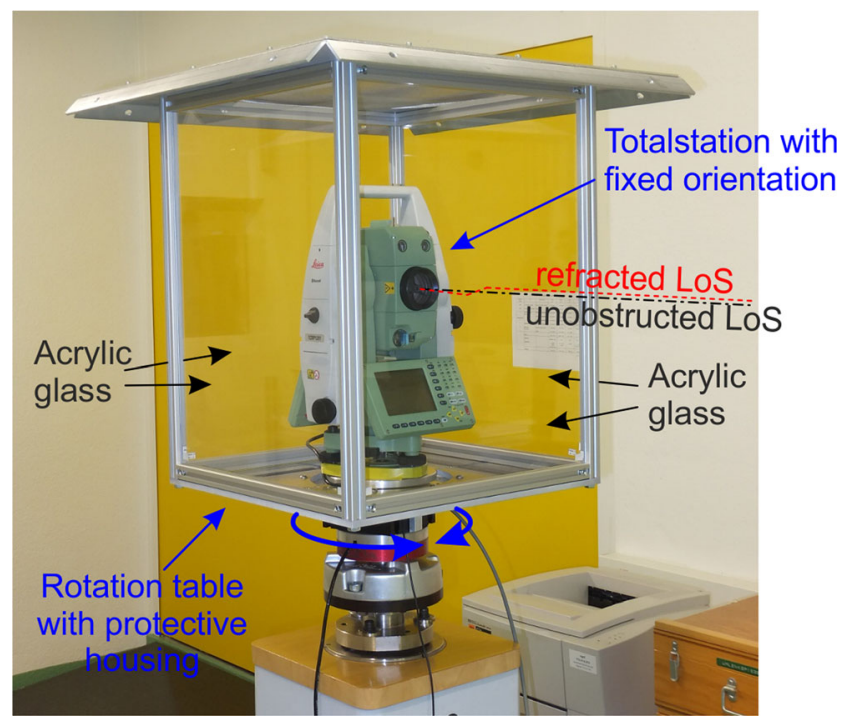

Fig. 5 An experimental setup to investigate the impact of protective housing on the RTS measurements 
Fig. 6 Variation of total station measurements as a function of angle between LoS and housing (surface normal of acrylic window); denser sampling for almost perpendicular line-of-sight ( 0 rotation angle) and for angles beyond 40 gon
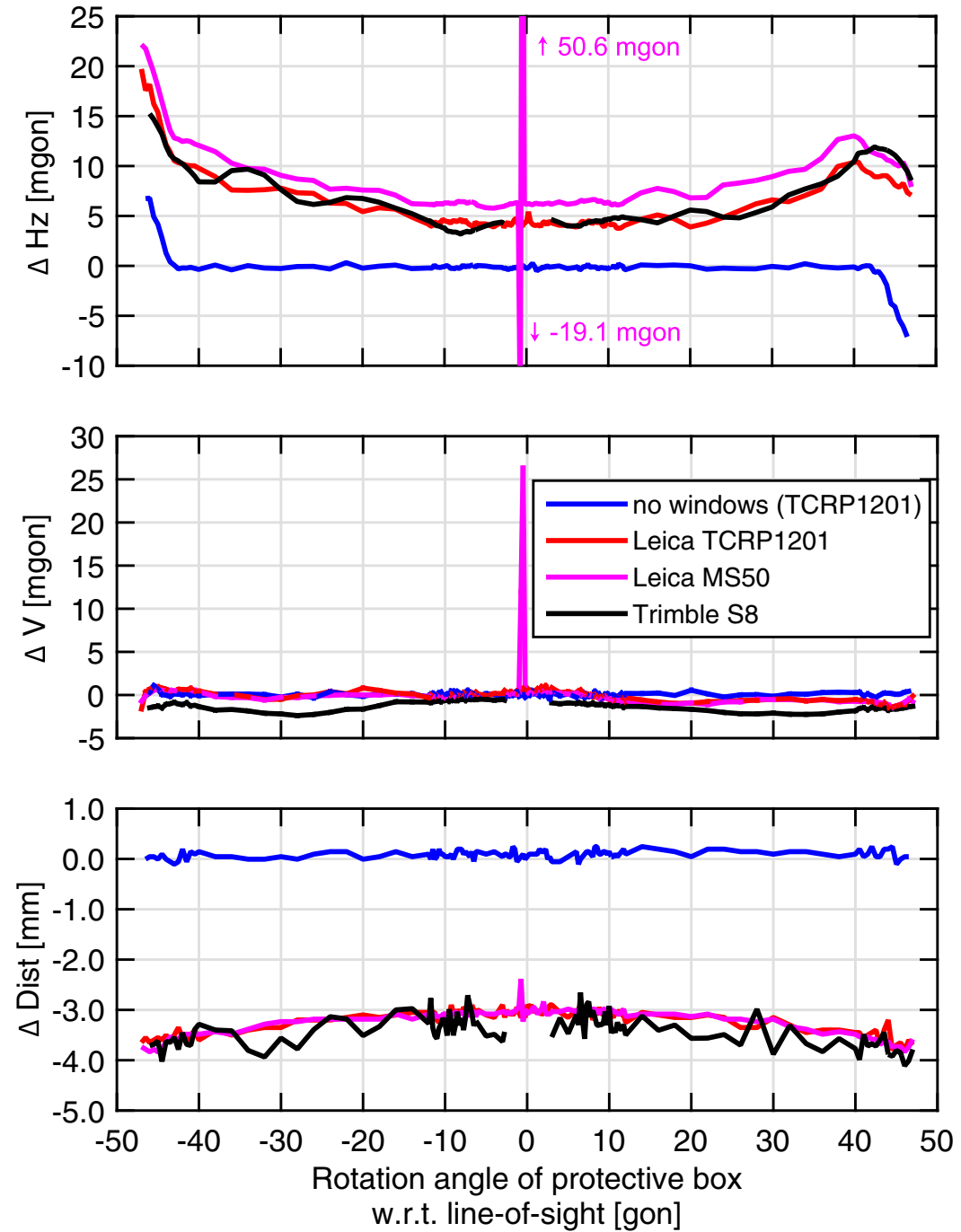

system is mounted. The housing within the above monitoring system was replaced by opaque cylinders with such holes.

\section{Pillar stability}

Both total stations are mounted on 1.5-m-high aluminum pillars consisting of two concentric pipes with no mechanical connection between the outer and inner ones. They are screwed down independently on bedrock with bolts glued into the rock. The outer pillar serves for radiation and weather protection and has vents for air circulation. The inner one has a diameter of $0.21 \mathrm{~m}$ and carries both the total station and the GNSS antenna.

Analysis of long-term pillar stabilities in three geodetic networks in California (Langbein and Johnson 1997) showed time-correlated deviations of about $1-2 \mathrm{~mm} / \sqrt{\text { year }}$ which were identified as likely caused by random-walk motion of the deeper parts of the Earth's crust. Here, to investigate potential short-term pillar instabilities or deformations and their impact on the total station measurements, RTS2 was equipped with additional sensors. Calibrated thermocouples were equally distributed around the circumference of the inner pipe at three different heights and within vertical profiles. A biaxial geotechnical inclination sensor (Jewell D711-2B, $\pm 5^{\circ}$ range, temperature calibrated by the manufacturer) was mounted directly on the rock supporting the pillar. Two single-axis inclination sensors (Wyler Zerotronic type $3, \pm 10^{\circ}$ range) were connected to the top of the inner pillar in an orthogonal configuration. Additionally, a meteo-sensor measuring a variety of parameters was temporarily installed at this site.

The measurements of the Jewell sensor show that the solid rock supporting the pillar is not perfectly stable but tilts in correlation with solar radiation and air temperature. Figure 7 shows a time series of inclination measurements, air temperature, and solar radiation during 1 week in Oct/Nov 2015. The tilt increases towards north by up to 20 " with a clear diurnal pattern closely resembling the variations of air temperature 

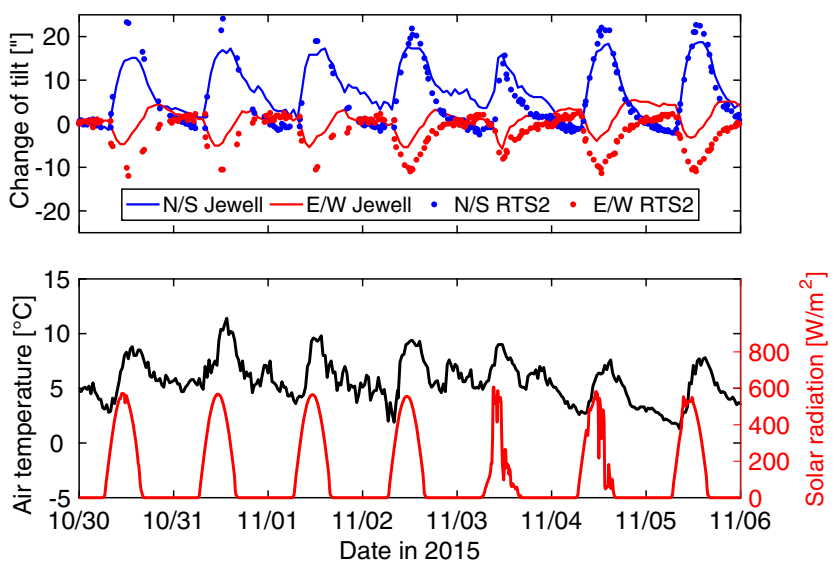

Fig. 7 Variation of rock inclination (Jewell) and total station tilt (RTS2) north/south and east/west directions at site RTS2 (top) and air temperature and solar radiation (bottom)

and solar radiation. There is a smaller inclination towards west in the morning and towards east in the evening. The inclination recorded by the inclination sensor of the total station agrees well with the rock inclinations in terms of signature and sign, but it is larger by up to $10^{\prime \prime}$.

We expected that this might be due to pillar bending. However, a calculation of the pillar deformation using a finite element model (FEM) and the actually measured temperature differences within the pillar did not fully explain the difference. The temperature differences within horizontal sections of the pillar (i.e., along the circumference) were typically well below $1{ }^{\circ} \mathrm{C}$ (they were up to about $3^{\circ}$ within the vertical profiles, which is not relevant for pillar bending). The deformations predicted by the FEM software corresponded to inclination changes of 3-5" or less between the bottom and the top of the pillar.

The residual difference between the sensed inclinations can be due to pillar tilt (at its base), uncompensated temperature effects of the sensors involved, or unbalanced thermal expansion effects of the tribrach or of the total station itself. Unfortunately, data from the inclination sensors (Wyler) on the top of the pillar, from those in the rock, and from the thermocouples could not be collected at the same time, and additionally, the sensors on the top of the pillar and their consoles were exposed to direct sunlight, which increased the noise level significantly and possibly also biased their measurements. So, a direct comparison and clarification of the reason for the apparent additional inclination of the total station were not yet possible. However, the available data from the Wyler sensors suggest that there may actually be a discrepancy of a few arc seconds between the top of the pillar and the total station.

The total station's measurements are not directly affected by the small tilts discussed so far because of the internal inclination corrections. However, tilt of rock, pillar, and instrument and bending of the pillar also cause a displacement of the total station's reference point. A numerical analysis assuming that the pillar, tribrach, and total station are perfectly rigid and the tilt variation indicated by the total station thus represents the tilt variation of all three elements yields horizontal displacements of the total station of less than $0.2 \mathrm{~mm}$, predominantly towards north-north-west (see Fig. 8), which is also the direction of the steepest uphill slope. The pillar bending as resulting from the FEM analysis is even less. So, these effects will very likely be buried within noise and other systematic deviations of the total station measurements.

However, so far, it is not known how the rock deforms in response to temperature and radiation changes, and thus the rock tilt changes mentioned above cannot be transformed into equivalent displacements of the total stations. We must expect that the diurnal patterns due to this effect are of the same order of magnitude as the $0.2 \mathrm{~mm}$ estimated above or even larger. Figure 7 shows that the rock tilts are relatively constant during and between the nights. This is one motivation to use primarily measurements obtained during the night for highly sensitive deformation and displacement analysis.

Using the FEM and the available temperature measurements of the pillar, diurnal height changes of the pillar of typically around $0.5 \mathrm{~mm}$ but up to $1 \mathrm{~mm}$ (with $30 \mathrm{~K}$ temperature differences between day and night) were predicted. For nearby target points (distance of a few $100 \mathrm{~m}$ ), this may noticeably affect the vertical angle measurements (on the level of a few 0.1 mgon) and may warrant correction of the measurements for this timevarying vertical eccentricity. An additional eccentricity of at least the same order of magnitude may be caused also by thermal expansion of the supporting rock, and further

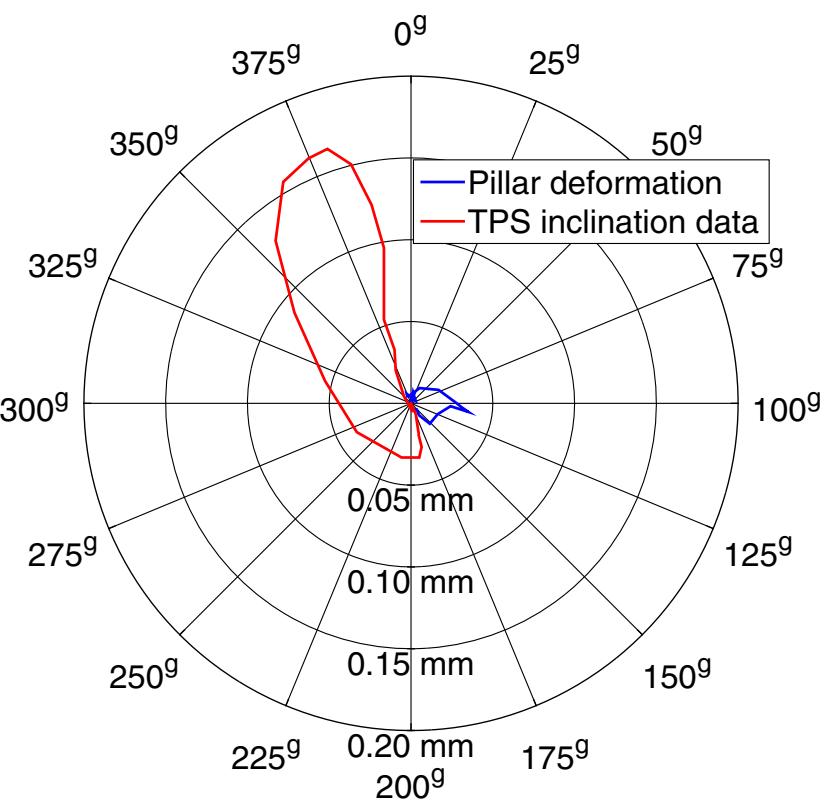

Fig. 8 Displacement of RTS2 corresponding to the total station tilt measurements of 30 August 2015 assuming a rigid pillar and tribrach (red) and contribution by pillar bending as estimated from FEM and thermocouple measurements (blue) 
investigations would be required to clarify its impact. However, refraction will mask all these effects for larger distances.

\section{Atmospheric refraction}

The effects discussed in the "Protective housing" and "Pillar stability" sections do not explain the systematic variations of the zenith angles and distances visible, e.g., in Fig. 3. Most likely, they are caused by residual atmospheric refraction. Although these refraction effects can be examined for long time series using differential observations (Stiros et al. 2004) and spectral analysis of residuals after extracting the deformation trend (Pytharouli et al. 2007), mitigating these effects for a near real-time monitoring using numerical models is not possible because the atmospheric parameters are not known or observable with sufficient spatial and temporal resolution. In this section, we will instead roughly estimate the magnitude and variability of the expected refraction effects using approximations, assumptions, and available meteo data and thus assess whether the unexplained variations of the actual measurements can plausibly be attributed to refraction.

Meteorological data relevant for this study are available from (1) two meteo-sensors (STS Sensor Technik Sirnach type DTM.OCS.S; air temperature and barometric pressure) located next to the RTS and used to record measurements every $30 \mathrm{~min}$ for correction of the raw RTS measurements within the GeoMoS software; (2) MeteoSwiss stations Bruchji (2300 m a.s.l.; air temperature and precipitation) and Eggishorn (2893 m a.s.l.; temperature, pressure, humidity, and solar radiation) with 10-min time resolution, see Fig. 9; and (3) sensors for rock temperature and air temperature $0.15 \mathrm{~m}$ above rock, installed on selected locations at the south and north slopes of the valley and recording measurements with 30-min time resolution.

From these data, vertical temperature gradients $\tau$ (lapse rates, in $\mathrm{K} / \mathrm{m}$ ) were roughly estimated as a function of time $t$ and height $h$ above ground assuming that the exponential relation (Brocks 1948):

$\tau(h, t)=a(t) \cdot h^{b(t)}$

holds within the entire monitoring area. The time series of $a$ and $b$ were calculated for epochs $30 \mathrm{~min}$ apart using the temperature measurements within the rock and $15 \mathrm{~cm}$ above the rock (assumed to represent the lapse rate at $7.5 \mathrm{~cm}$ above ground) at a location close to prism 17 and the temperature measurements at the two MeteoSwiss stations (assumed to represent the lapse rate at $300 \mathrm{~m}$ above ground).

The result is shown in Figs. 10 and 11 for the vicinity of RTS1 and 1 month in summer 2015. Just above the ground, the estimated lapse rate has a very high magnitude (exceeding $-50 \mathrm{~K} / \mathrm{m}$, Fig. 10) and significant diurnal variations (up to
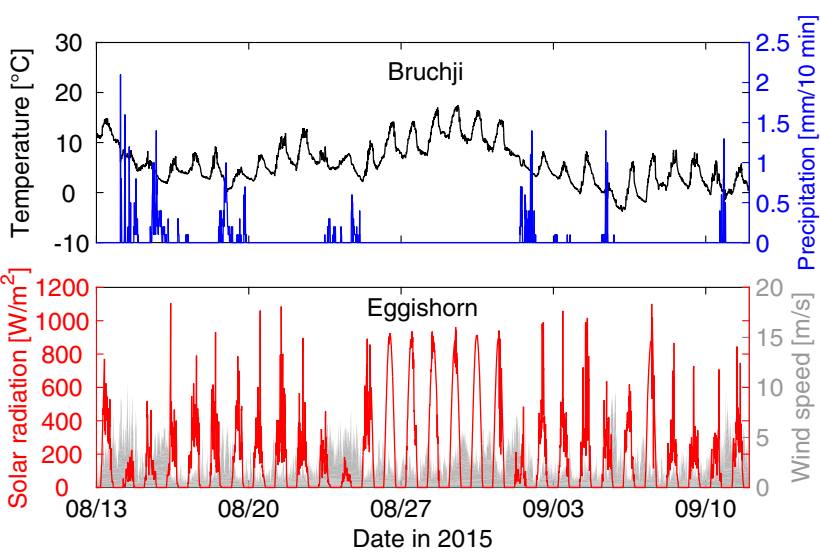

Fig. 9 Air temperature (black), precipitation (blue), solar radiation (red), and wind speed (gray) at two nearby MeteoSwiss stations (source: MeteoSwiss)

$10 \mathrm{~K} / \mathrm{m}$, Fig. 11). The daily variations and the magnitude of the lapse rate decrease with increasing distance from the ground. Even though the above assumptions can only be very rough approximations to the real temperature gradients, this pattern is realistic and the typical lapse rate of a glaciated alpine valley $(-0.005 \mathrm{~K} / \mathrm{m}$, see Rolland 2003$)$ is reached at about $300 \mathrm{~m}$ above the ground. It is worth mentioning that the expected temperature inversion during the nights was not observed except during one single night (24-25 August 2015) after a cloudy day with wind and rain.

When adapting these models, we do not take into account the cooling effect of the melting as mentioned in Van der Broeke (1997). This effect extends to a height of about $100 \mathrm{~m}$ above the glacier with the most pronounced effects within the first $20 \mathrm{~m}$ where it causes an inverted lapse rate of about $0.7 \mathrm{~K} / \mathrm{m}$ during sunny summer days. We ignore this effect because the LoS in our case are high above the glacier.

Using the above meteo data and temperature gradient model, pressure gradients calculated from the meteo data, and a refractive index model (Ciddor 1996; Ciddor and Hill 1999) taking into account the respective wavelengths and using a digital terrain model of the monitoring area (Swisstopo model with

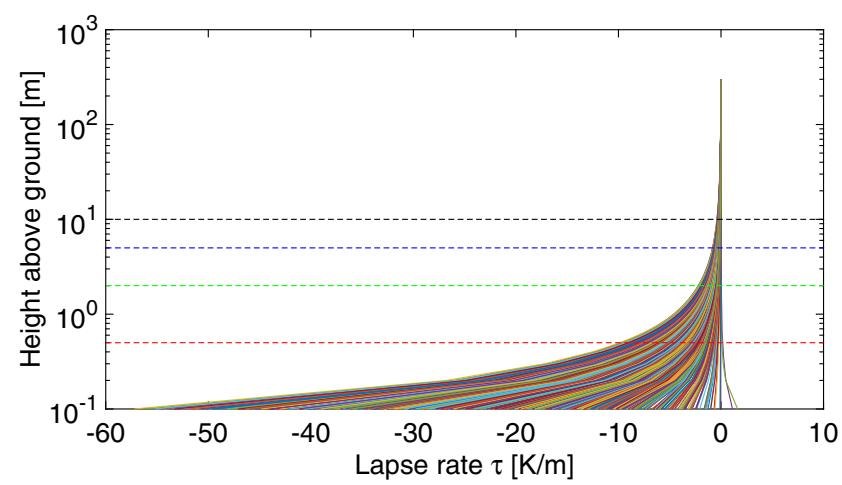

Fig. 10 Estimated temperature gradient as a function of height above ground in the vicinity of RTS1 for the time covered by Fig. 9; each line corresponds to an epoch with 30-min time resolution 


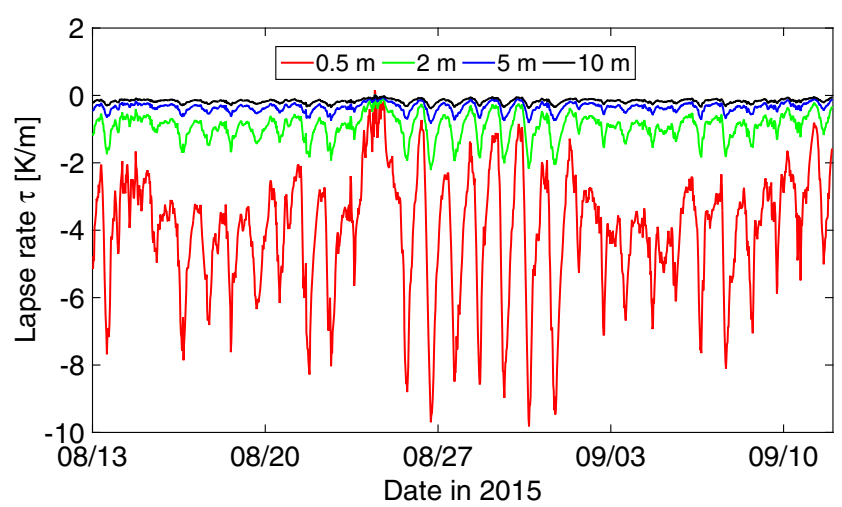

Fig. 11 Time series of estimated temperature gradients at the vicinity of RTS1 and four selected heights above ground

$2 \times 2 \mathrm{~m}^{2}$ grid size, densification with own laser scanning measurements in the vicinity of the total stations), we estimated the refraction effect on the zenith angles and distances by ray tracing. The software was written in Matlab. For each target and epoch, meteo-parameters and gradients were calculated for points equally spaced along the chord using the above models. Taking into account the DTM resolution, the limited accuracy of the modeled meteorological parameters, the computational effort, and the purpose of the calculations (order of magnitude), we chose a step size of $1 \mathrm{~m}$ for the numeric integration along the chord. In Figs. 12 and 13, we show the resulting zenith angle and distance variations for 1 month in summer 2015 and for two representative LoS, as previously shown in Fig. 2: one across and one along the valley. For comparison, we also plotted the variation of the real total station measurements.

As can be seen, the variations of the predicted zenith angles have a magnitude of about 1 mgon for the sighting across and 3 mgon for the sighting along the valley. They are in good agreement with the magnitude of the actually observed vertical angle variations which suggests that these indeed are due to vertical refraction. It is plausible that the effect is much smaller for the sighting across the valley (Fig. 12) than along (Fig. 13), because the LoS stays close to the ground and thus within an area of strong vertical temperature gradient and with significant atmospheric turbulence (Brunner 1982) in the latter case, while it is mostly far from the ground and thus within an area where the vertical refraction is dominated by the (much less variable) pressure gradient in the former one. ${ }^{3}$

The long-term variations of the distance measurements are well represented by the ray-tracing results. However, standard meteo correction based on temperature and pressure close to the instrument would yield almost identical results since the simplified meteo model underlying the ray tracing does not reflect the actual temperature distribution along the LoS. The major variations of the actually observed distances (Figs. 12 and 13 bottom,

\footnotetext{
${ }^{3}$ As stated above, it is not possible to calculate sufficiently accurate refraction corrections because the meteo data (including gradients) are not available along the LoS and for the exact time of the measurement.
}

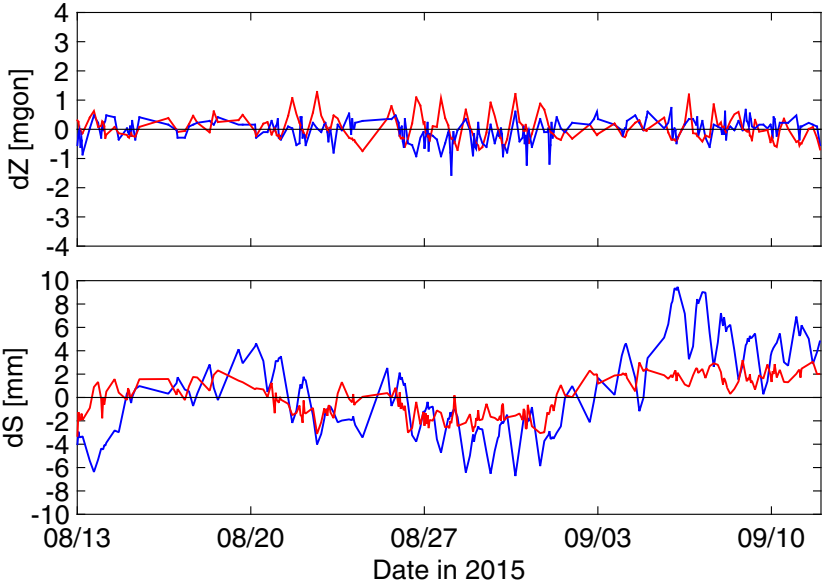

Fig. 12 Refraction effect (red) predicted for zenith angle (top) and residual refraction effect of distance after ray tracing (bottom) of point 4 observed from RTS1 at approx. $1200 \mathrm{~m}$ across the valley; variation of actual RTS measurements (blue) w.r.t. long-term median shown for comparison

blue) are short term, in particular with diurnal patterns, and much larger than the variations explained by the ray tracing. With distances of about 1 to $1.2 \mathrm{~km}$, the deviations between raytracing results and actual variation are up to about $4 \mathrm{~mm}$. This indicates that the actual average temperature along the LoS differs by up to about $4 \mathrm{~K}$ from the modeled one (and from the temperature measurements at the RTS site). This may be due to different exposure to sunlight, to the cooling effect of the glacier mentioned previously, and perhaps also to non-optimum location of the meteo-sensors near the total stations. Taking into account the striking similarity of the variations of the measured distances across and along the valley, it seems possible to mitigate these variations either by estimation of a time-varying local scale factor or by improved meteo corrections based on additional meteo measurements near some of the prisms.
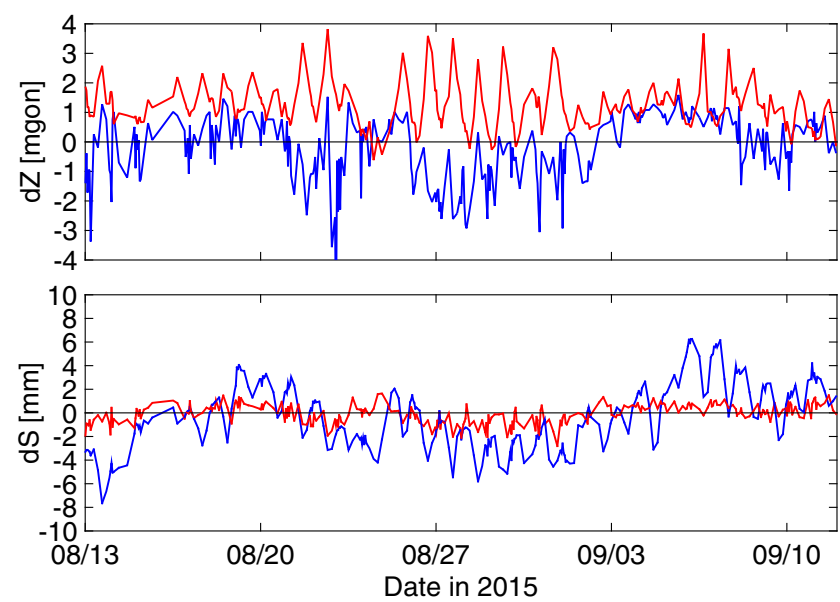

Fig. 13 Refraction effect (red) predicted for zenith angle (top) and residual refraction effect of distance after ray tracing (bottom) of point 18 observed from RTS1 at approx. $1000 \mathrm{~m}$ along the slope of the valley; variation of actual RTS measurements (blue) w.r.t. long-term median shown for comparison 
Fig. 14 Displacements obtained using the Hannover method between two selected epochs (13 April 2014 and 31 July 2014).

The red arrows identify the displacements of the object points of RTS1, identified as instable with $95 \%$ probability using the Hannover method. Object points are labeled in red and reference points in green; black points do not have enough observations for a comparison (background image (C) 2015 swisstopo, JD100042)

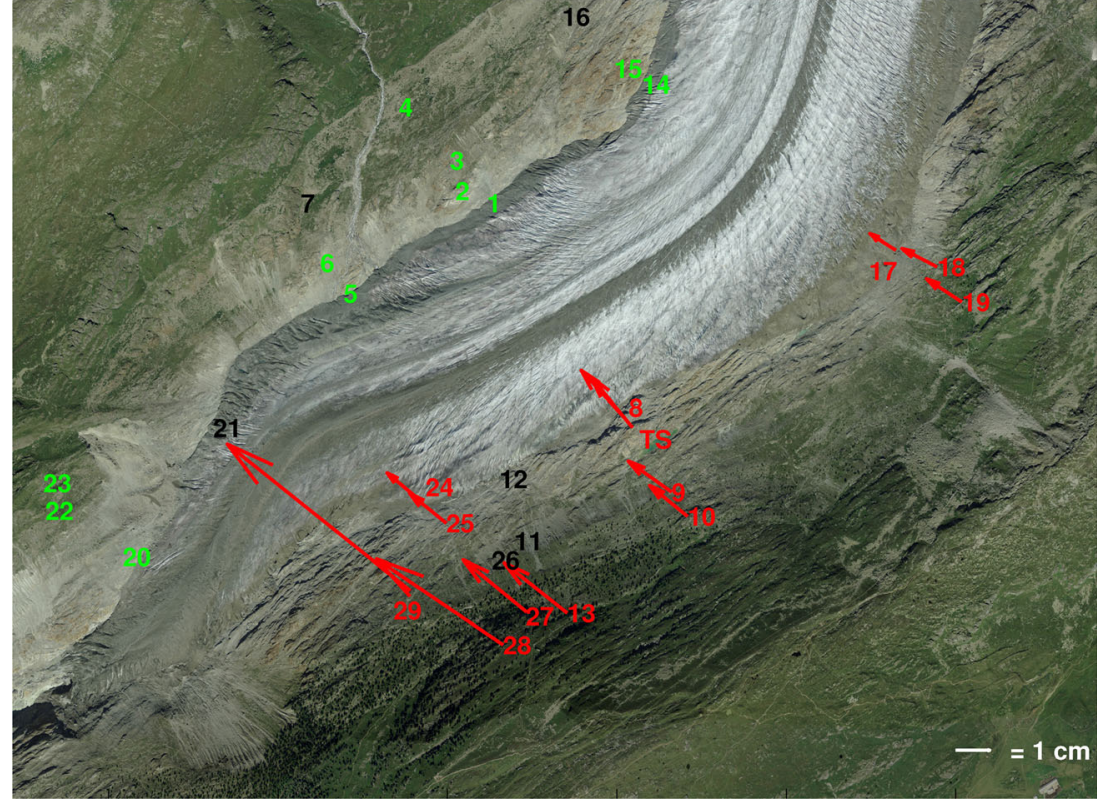

\section{Orientation}

For data collection, a nearby prism (i.e., one with high probability of being actually found and measured) was selected in GeoMoS as orientation target. However, the horizontal angles of each individual target point obtained with this approximate orientation vary within a range of 1-2 mgon during the nights and by up to 4 mgon during the days, for some points even more. Clearly, a better orientation solution is required avoiding extrapolation, providing redundancy, and assuring long-term stability of the orientation. As mentioned previously, this is not straightforward in this monitoring system because no stable points were known beforehand. GNSS data are available at the RTS sites, but there are not yet any prisms collocated with GNSS antennas. So, the reference points defining the total station's orientation have to be determined using the RTS alone data.

Although there is no geometric redundancy and the expected accuracies of the points are very inhomogeneous being a linear function of the distance, data of RTS1 were processed according to a strict deformation analysis based on the Hannover method (Niemeier 1985) using the Panda software. ${ }^{4}$ Data from selected nights 10 days to 3.5 months apart were chosen for pairwise analysis. The results of one such pair, shown in Fig. 14, are representative: all points on the northwest slope were classified as reference points, i.e., as stable, while all points on the same side of the valley as the RTS were classified as object points, i.e., as not stable. The indicated displacement of the RTS station corresponds approximately to its displacement as resulting from the independent GNSS data analysis (about $15 \mathrm{~mm}$ in a direction of about $293^{\circ}$ ), and the bigger displacement of points 24-29 in the direction of the downhill dip is plausible since these points

$\overline{4}$ http://www.geotec-gmbh.de/en/panda/ are located on an active landslide. The common displacement of the southern points in Fig. 14 would be explainable by the narrowing of the valley mentioned in the introduction. GNSS data of RTS2 were not yet available for that period of time. However, data from the following year suggest that indeed there may be no or significantly less corresponding displacement of the north side of the valley, such that the classification of all those points as stable may be correct.

However, a detailed comparison of these results with the GNSS time series shows that only the north component (of about $12 \mathrm{~mm}$ ) is almost identical while the east component differs by more than $5 \mathrm{~mm}$ and the RTS results of all epochs analyzed indicate significantly more westward displacements of than shown by the GNSS results. The lack of actually stable reference points and the inhomogeneous accuracy within the observed point field (with larger error ellipses and thus decreased sensitivity for the points across the valley) mean that the Hannover method using only the RTS measurements is not sufficient.

Based on the available data, it seems more reasonable to use a low-pass filtered time series of GNSS coordinates to express the RTS coordinates in a stable reference frame and to calculate the orientation from the network. ${ }^{5}$ Assuming that the points within the profiles are displaced only by the narrowing and widening of the valley and thus within the profile, it seems straightforward to define the orientation by the average direction of the prisms in the same profile as the RTS. However, we have chosen to find a suitable set of prisms by analyzing the real measurements (processing only data obtained during the nights because of less variability).

\footnotetext{
${ }^{5}$ Ideally, some prisms should be collocated with GNSS antennas to derive the orientation within the same stable reference frame. This is an envisaged future extension of the network.
} 
Fig. 15 Angle availability (\%) for period 15 March 2014 to 3 August 2014

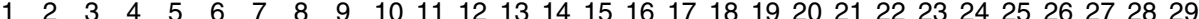

\begin{tabular}{|c|c|c|c|c|c|c|c|c|c|c|c|c|c|c|c|c|}
\hline & 77 & 74 & 70 & 55 & 75 & 75 & 9 & 77 & 62 & 70 & 18 & 8 & 73 & 74 & 73 & \\
\hline 2 & 74 & 76 & 73 & 55 & 74 & 74 & $y$ & 75 & 61 & 69 & 18 & 8 & 72 & 74 & 73 & 6 \\
\hline & 70 & 73 & 74 & 56 & 73 & 73 & 8 & 73 & 60 & 67 & 17 & 8 & 71 & 72 & 72 & 6 \\
\hline 4 & 55 & 55 & 56 & 56 & 56 & 56 & 5 & 56 & 44 & 50 & 14 & 7 & 56 & 56 & 56 & 6 \\
\hline 5 & 75 & 74 & 73 & 56 & 77 & 75 & 9 & 77 & 63 & 70 & 18 & 8 & 74 & 74 & 73 & 6 \\
\hline & 75 & 74 & 73 & 56 & 75 & 77 & 9 & 76 & 63 & 70 & 18 & 8 & 73 & 73 & 73 & 6 \\
\hline & 9 & 9 & 8 & 5 & 9 & 9 & 9 & 9 & 9 & 9 & 9 & 3 & 7 & 8 & 8 & 0 \\
\hline & 77 & 75 & 73 & 56 & 77 & 76 & 9 & 84 & 66 & 73 & 19 & 8 & 75 & 75 & 74 & 6 \\
\hline & 62 & 61 & 60 & 44 & 63 & 63 & 9 & 66 & 67 & 65 & 9 & 7 & 61 & 60 & 60 & 4 \\
\hline & 70 & 69 & 67 & 50 & 70 & 70 & 9 & 73 & 65 & 89 & 15 & 8 & 69 & 67 & 67 & 5 \\
\hline & 18 & 18 & 17 & 14 & 18 & 18 & 9 & 19 & 9 & 15 & 19 & 3 & 18 & 18 & 18 & 2 \\
\hline & 8 & 8 & 8 & 7 & 8 & 8 & 3 & 8 & 7 & 8 & 3 & 8 & 8 & 8 & 8 & 0 \\
\hline & 73 & 72 & 71 & 56 & 74 & 73 & 7 & 75 & 61 & 69 & 18 & 8 & 76 & 72 & 71 & 6 \\
\hline & 74 & 74 & 72 & 56 & 74 & 73 & 8 & 75 & 60 & 67 & 18 & 8 & 72 & 75 & 73 & 6 \\
\hline & 73 & 73 & 72 & 56 & 73 & 73 & 8 & 74 & 60 & 67 & 18 & 8 & 71 & 73 & 74 & 6 \\
\hline & 6 & 6 & 6 & 6 & 6 & 6 & 0 & 6 & 4 & 5 & 2 & 0 & 6 & 6 & 6 & 6 \\
\hline & 58 & 58 & 57 & 42 & 59 & 59 & 8 & 61 & 59 & 60 & 9 & 8 & 58 & 57 & 58 & 3 \\
\hline & 71 & 71 & 70 & 54 & 72 & 72 & 9 & 74 & 62 & 68 & 18 & 8 & 72 & 71 & 71 & 6 \\
\hline & 70 & 70 & 69 & 53 & 71 & 71 & 8 & 73 & 60 & 67 & 18 & 8 & 71 & 70 & 69 & 6 \\
\hline & 12 & 12 & 12 & 11 & 12 & 12 & 0 & 12 & 9 & 10 & 2 & 1 & 12 & 12 & 12 & 3 \\
\hline & 7 & 7 & 7 & 4 & 7 & 7 & 7 & 7 & 7 & 7 & 7 & 2 & 7 & 7 & 7 & 0 \\
\hline & 29 & 29 & 29 & 27 & 28 & 29 & 2 & 29 & 22 & 25 & 7 & 5 & 29 & 29 & 29 & 6 \\
\hline & 58 & 58 & 59 & 51 & 56 & 57 & 7 & 59 & 48 & 54 & 16 & 7 & 59 & 59 & 59 & 6 \\
\hline & 65 & 64 & 64 & 49 & 65 & 65 & 8 & 67 & 60 & 65 & 13 & 8 & 64 & 65 & 64 & 4 \\
\hline & 74 & 73 & 71 & 55 & 74 & 72 & 8 & 76 & 62 & 70 & 18 & 8 & 73 & 72 & 72 & 6 \\
\hline & 26 & 26 & 25 & 16 & 26 & 26 & 8 & 26 & 26 & 25 & 9 & 5 & 25 & 25 & 25 & 1 \\
\hline & 71 & 71 & 71 & 54 & 73 & 73 & 8 & 74 & 61 & 68 & 18 & 8 & 70 & 72 & 71 & 6 \\
\hline & 72 & 72 & 71 & 56 & 73 & 73 & 8 & 74 & 61 & 68 & 18 & 8 & 73 & 72 & 71 & 6 \\
\hline & 56 & 56 & 56 & 44 & 57 & 57 & $\gamma$ & 57 & 55 & 57 & 8 & & 56 & 56 & 56 & 4 \\
\hline
\end{tabular}

\begin{tabular}{|c|c|c|c|c|c|c|c|c|c|c|c|c|}
\hline 88 & 71 & 70 & 12 & & 29 & 58 & 65 & 74 & 26 & 71 & 72 & 56 \\
\hline 58 & 71 & 70 & 12 & 7 & 29 & 58 & 64 & 73 & 26 & 71 & 72 & 56 \\
\hline 57 & 70 & 69 & 12 & 7 & 29 & 59 & 64 & 71 & 25 & 71 & 71 & 56 \\
\hline 42 & 54 & 53 & 11 & 4 & 27 & 51 & 49 & 55 & 16 & 54 & 56 & 44 \\
\hline 59 & 72 & 71 & 12 & 7 & 28 & 56 & 65 & 74 & 26 & 73 & 73 & 57 \\
\hline 59 & 72 & 71 & 12 & 7 & 29 & 57 & 65 & 72 & 26 & 73 & 73 & 57 \\
\hline 8 & 9 & 8 & 0 & 7 & 2 & f & 8 & 8 & 8 & 8 & 8 & 7 \\
\hline 61 & 74 & 73 & 12 & 7 & 29 & 59 & 67 & 76 & 26 & 74 & 74 & 57 \\
\hline 59 & 62 & 60 & 9 & 7 & 22 & 48 & 60 & 62 & 26 & 61 & 61 & 55 \\
\hline 50 & 68 & 67 & 10 & 7 & 25 & 54 & 65 & 70 & 25 & 68 & 68 & 57 \\
\hline 9 & 18 & 18 & 2 & 7 & 7 & 16 & 13 & 18 & 9 & 18 & 18 & 8 \\
\hline 8 & 8 & 8 & 1 & 2 & 5 & 7 & 8 & 8 & 5 & 8 & 8 & 8 \\
\hline 58 & 72 & 71 & 12 & 7 & 29 & 59 & 64 & 73 & 25 & 70 & 73 & 56 \\
\hline 57 & 71 & 70 & 12 & 7 & 29 & 59 & 65 & 72 & 25 & 72 & 72 & 56 \\
\hline 58 & 71 & 69 & 12 & 7 & 29 & 59 & 64 & 72 & 25 & 71 & 71 & 56 \\
\hline 3 & 6 & 6 & 3 & 0 & 6 & 6 & 4 & 6 & 1 & 6 & 6 & 4 \\
\hline 62 & 59 & 57 & 8 & 7 & 21 & 46 & 57 & 59 & 26 & 58 & 58 & 53 \\
\hline 59 & 75 & 71 & 12 & 7 & 28 & 58 & 64 & 72 & 25 & 71 & 71 & 57 \\
\hline 57 & 71 & 73 & 12 & 7 & 28 & 57 & 64 & 71 & 24 & 70 & 71 & 56 \\
\hline 8 & 12 & 12 & 12 & 0 & 10 & 10 & 10 & 12 & 2 & 12 & 12 & 10 \\
\hline 7 & 7 & 7 & 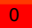 & 7 & 2 & 6 & 7 & 7 & 7 & 7 & 7 & 6 \\
\hline 21 & 28 & 28 & 10 & 2 & 29 & 27 & 24 & 29 & 9 & 29 & 29 & 23 \\
\hline 46 & 58 & 57 & 10 & 6 & 27 & 59 & 52 & 57 & 20 & 58 & 59 & 47 \\
\hline 57 & 64 & 64 & 10 & 7 & 24 & 52 & 68 & 65 & 24 & 64 & 64 & 56 \\
\hline 59 & 72 & 71 & 12 & 7 & 29 & 57 & 65 & 76 & 26 & 73 & 72 & 57 \\
\hline 26 & 25 & 24 & 2 & 7 & 9 & 20 & 24 & 26 & 27 & 25 & 25 & 23 \\
\hline 58 & 71 & 70 & 12 & 7 & 29 & 58 & 64 & 73 & 25 & 74 & 73 & 56 \\
\hline 58 & 71 & 71 & 12 & 7 & 29 & 59 & 64 & 72 & 25 & 73 & 74 & 56 \\
\hline 53 & 57 & 56 & 10 & 6 & 23 & 47 & 56 & 57 & 23 & 56 & 56 & 57 \\
\hline
\end{tabular}

\begin{tabular}{|cccccccccc|}
\hline & 1 & 1 & 1 & 1 & 1 & 1 & 1 & 1 & 1 \\
\hline 0 & 10 & 20 & 30 & 40 & 50 & 60 & 70 & 80 & 90
\end{tabular}

The approach was based on an analysis of the availability and empirical standard deviation of the orientation as resulting from a chosen subset of points. For preselection of points, the time series of horizontal angles $\alpha_{i, j}$ were calculated for all pairs of points $i$ and $j$ and for the period March to August 2014. Using the median and the median absolute deviation (MAD), outliers were identified and removed from the time series. Then, the availability (percentage of epochs at which the angle is available) and the empirical standard deviation of the angle were calculated. These results were visualized for all pairs of points (see Figs. 15 and 16). Points associated with high availability and low standard deviation of angles were chosen as candidates for the orientation calculation. Arbitrarily, a 50\% availability threshold and a 0.6-mgon standard deviation threshold were used for this selection.

Then, an exhaustive search over all possible combinations of at least 5 out of the 18 points remaining after the above preselection was carried out analyzing the availability and precision of the orientation when calculated from the respective subset of points. For each epoch, the orientation was
Fig. 16 Empirical standard deviations (mgon) of horizontal angles for period 15 March 2014 to 3 August 2014

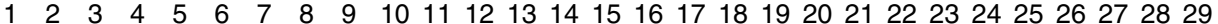

\begin{tabular}{|c|c|c|c|c|c|c|c|c|c|c|c|c|c|c|c|c|c|c|c|c|c|c|c|c|c|c|c|c|}
\hline .0 & & & & 0.4 & 0.3 & 0.3 & & .4 & 0.3 & 0.4 & 0.7 & 0.4 & .4 & 0.4 & 0.3 & 0.4 & 0.4 & 0.4 & 0.6 & 0.5 & 0.5 & 0.5 & 0.5 & 0.5 & 0.3 & 0.4 & 0.9 & \\
\hline 0.3 & 0.0 & .2 & .3 & 0.4 & 3 & 0.3 & 0.9 & 0.4 & 0.3 & 3 & .7 & 0.4 & .4 & 0.4 & 0.3 & 0.4 & .4 & 0.4 & 6 & 0.4 & 0.5 & 0.5 & .5 & 0.4 & 0.3 & 0.4 & .9 & 1.2 \\
\hline 0.2 & .2 & 0 & 0.3 & 0.4 & .4 & 0.3 & 0.9 & 0.4 & 0.3 & 3 & 0.7 & 0.4 & 0.4 & 0.4 & 0.3 & 0.4 & 0.4 & 0.3 & 0.6 & 0.4 & 0.5 & .5 & 0.5 & 0.5 & 0.3 & 0.4 & .9 & 1.2 \\
\hline 0.3 & 3 & 0.3 & 0.0 & 0.5 & 4 & 0.4 & 1.0 & 0.4 & 0.4 & 0.4 & 0.6 & 0.4 & 0.5 & 0.4 & 0.3 & 0.4 & 0.4 & 0.4 & 0.6 & 0.5 & 0.5 & .5 & 0.5 & 0.5 & .4 & .4 & .9 & 1.1 \\
\hline 0.4 & 0.4 & 4 & .5 & 0.0 & 0.3 & .4 & 0.7 & 0.6 & 0.5 & 0.5 & 0.7 & 0.6 & 0.7 & .6 & 0.6 & 0.5 & 0.6 & .5 & 0.4 & 0.4 & 0.4 & .3 & 0.4 & 0.3 & .4 & .6 & 1.2 & 1.4 \\
\hline 0.3 & .3 & .4 & .4 & .3 & 0.0 & 0.3 & 0.8 & 0.5 & 0.4 & 0.5 & 0.7 & 0.5 & 0.6 & 0.6 & 0.5 & 0.5 & 0.5 & 0.5 & 0.4 & 0.4 & 0.4 & .3 & 0.4 & 0.3 & .3 & .5 & 1.1 & 1.3 \\
\hline 0.3 & 0.3 & 0.3 & 0.4 & .4 & 0.3 & 0.0 & ). 6 & 0.3 & 0.2 & 0.3 & 0.9 & 0.2 & 0.4 & 0.3 & 0.0 & 0.4 & 0.5 & 0.4 & 0.0 & 0.4 & 0.5 & .4 & 0.4 & 0.4 & .3 & 0.3 & 0.3 & 0.5 \\
\hline 0.9 & .9 & 1.9 & .0 & 0.7 & 0.8 & 0.6 & 0.0 & 1.0 & 1.0 & 1.3 & 0.7 & 1.1 & 1.2 & 1.1 & 1.0 & 0.9 & 1.0 & 1.0 & 0.6 & 0.6 & 0.7 & 0.8 & 0.8 & 0.8 & 0.7 & 1.1 & 1.7 & 1.8 \\
\hline 0.4 & 0.4 & .4 & 0.4 & 0.6 & 0.5 & 0.3 & 1.0 & 0.0 & 0.2 & 0.3 & 0.6 & 0.2 & 0.3 & 0.3 & 3 & 0.4 & 0.4 & 0.4 & 0.7 & 0.4 & 0.6 & 6 & .6 & 0. & 0.3 & 0.3 & .6 & 0.9 \\
\hline 0.3 & 0.3 & 0.3 & .4 & 0.5 & 0.4 & 0.2 & 1.0 & 0.2 & 0.0 & 3 & 0.6 & 0.2 & 0.3 & .3 & 3 & 0 & 0.4 & 0.4 & 6 & 0.3 & 0.5 & 6 & .6 & 0.5 & .3 & 0.2 & .7 & 1.0 \\
\hline 0.4 & 0.3 & 0.3 & 0.4 & .5 & 0.5 & 0.3 & 1.3 & 0.3 & 0.3 & 0.0 & .7 & 0.4 & 0.6 & 0.5 & .3 & 0.5 & 0.5 & 0.5 & 0.5 & 0.4 & 0.6 & .6 & .5 & 0.5 & .3 & .4 & 1.2 & 0.6 \\
\hline 0.7 & 0.7 & .7 & 0.6 & .7 & 0.7 & 0.9 & 0.7 & 0.6 & 0.6 & 0.7 & 0.0 & 0.6 & 0.8 & 0.8 & .4 & 0.8 & 0.8 & 0.8 & .7 & 0.8 & 0.7 & .7 & .7 & 6 & 0.7 & 0.7 & 0.9 & 1.2 \\
\hline 0.4 & 0.4 & 0.4 & 0. & 6 & 0.5 & 0.2 & 1.1 & 0.2 & 0.2 & 0.4 & 0.6 & 0.0 & 0.4 & .4 & 0.4 & 0.5 & 0.5 & 0.4 & 0.6 & 0.4 & 0.6 & 0.7 & .6 & 0.6 & .3 & 0.2 & .7 & 0.9 \\
\hline 0.4 & 0.4 & 0.4 & 0.5 & .7 & 0.6 & 0 & 1.2 & 0.3 & 0.3 & 0.6 & 8 & 0.4 & 0.0 & 3 & .3 & 0.3 & 0.4 & 0.4 & 0.8 & 0.5 & 0.7 & .8 & .7 & 0.7 & .4 & .4 & .7 & 1.1 \\
\hline 0.4 & 0.4 & 0.4 & 0.4 & 6 & 0.6 & 0.3 & \begin{tabular}{|l|l} 
& 1.1
\end{tabular} & 0.3 & 0.3 & 0.5 & 0.8 & 0.4 & 0.3 & .0 & .3 & 0.4 & 0.4 & .4 & 0.8 & 0.4 & 0.7 & .7 & .6 & 0.7 & .4 & .4 & .7 & . \\
\hline 0.3 & 0.3 & 0.3 & 0.3 & 0.6 & 0.5 & 0.0 & 1.0 & 0.3 & 0.3 & 0.3 & 0.4 & 0.4 & 0.3 & 0.3 & 0.0 & 0.4 & 0.3 & 0.3 & 0.5 & 0.0 & 0.5 & 0.6 & 0.4 & 0.6 & 0.3 & 0.3 & 0.4 & 0.6 \\
\hline 0.4 & 0.4 & 0.4 & 0.4 & .5 & 0.5 & 0.4 & 0.9 & 0.4 & 0.4 & 0.5 & 0.8 & 0.5 & 0.3 & 0.4 & 0.4 & 0.0 & 0.4 & 0.3 & 0.6 & 0.5 & 0.6 & 0.6 & 0.6 & 0.5 & 0.5 & 0.5 & 0.9 & 1.2 \\
\hline 0.4 & 0.4 & 0.4 & 0.4 & 6 & 0.5 & 0.5 & 1.0 & 0.4 & 0.4 & 0.5 & 0.8 & 0.5 & 0.4 & 0.4 & 0.3 & 0.4 & 0.0 & 0.3 & 0.8 & 0.6 & 0.6 & 0.7 & 0.6 & 0. & 0.5 & 0.5 & 0.9 & 1.2 \\
\hline 0.4 & 0.4 & 0.3 & 0.4 & 0.5 & 0.5 & 0.4 & 1.0 & 0.4 & 0.4 & 0.5 & 0.8 & 0.4 & 0.4 & 0.4 & 0.3 & 0.3 & 0.3 & 0.0 & 0.7 & 0.6 & 0.6 & 0.6 & .6 & 0.6 & 0.4 & 0.5 & 0.8 & 1.2 \\
\hline 0.6 & 0.6 & 0.6 & 0.6 & 0.4 & 0.4 & 0.0 & 0.6 & 0.7 & 0.6 & 0.5 & 0.7 & 0.6 & 0.8 & 0.8 & 0.5 & 0.6 & 0.8 & 0.7 & 0.0 & 0.0 & 0.4 & 0.4 & 0.4 & 0.4 & 0.4 & 0.7 & 1.0 & 1.2 \\
\hline 0.5 & 0.4 & 0.4 & 0.5 & .4 & 0.4 & 0.4 & 0.6 & 0.4 & 0.3 & 0.4 & 0.8 & 0.4 & 0.5 & 0.4 & 0.0 & 0.5 & .6 & 0.6 & 0.0 & 0.0 & 0.5 & 0.5 & .6 & 0.5 & 0.4 & 0.5 & 0.5 & 0.6 \\
\hline 0.5 & 0.5 & 0.5 & 0.5 & 0.4 & 0.4 & 0.5 & 0. & 0.6 & 0.5 & 0.6 & 0 & 0.6 & 0.7 & .7 & 0.5 & 0.6 & 0.6 & 0.6 & 0.4 & 0.5 & 0.0 & 0.4 & 0.5 & 0.4 & 0.4 & 0.6 & 1.2 & 1.4 \\
\hline 0.5 & 0.5 & 0.5 & 0. & 0.3 & 0.3 & 0 & 0.8 & 0.6 & 0.6 & 0.6 & 0.7 & 0.7 & 0.8 & 0.7 & 0.6 & 0.6 & 0.7 & 0.6 & 0.4 & 0.5 & 0.4 & .0 & 0.4 & 0.4 & 0.4 & 0.7 & 1.2 & 1.4 \\
\hline 0.5 & 0.5 & 0.5 & 0.5 & 0.4 & 0.4 & 0.4 & 0.8 & 0.6 & 0.6 & 0.5 & 0.7 & 0.6 & .7 & 0.6 & 0.4 & 0.6 & 0.6 & 0.6 & 0.4 & 0.6 & 0.5 & .4 & 0.0 & 0.3 & 0.3 & 0.6 & 1.1 & 1.4 \\
\hline 0.5 & 0.4 & 0.5 & 0.5 & 0.3 & 0.3 & 0 & 0.8 & 0.5 & 0.5 & 0.5 & 0 & 0.6 & 0.7 & 0.7 & 0.6 & 0. & 0.6 & 0.6 & 0.4 & 0.5 & 0.4 & .4 & 3 & 0.0 & 0.3 & 0.6 & 1.1 & 1.3 \\
\hline 0.3 & 0.3 & 0.3 & 0.4 & 0.4 & 0.3 & 0.3 & 0.7 & 0.3 & 0.3 & 0.3 & 0.7 & 0.3 & 0.4 & 0.4 & 0.3 & 0. & .5 & 0.4 & 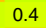 & 0. & 0.4 & 1.4 & 0.3 & 0.3 & 0.0 & .3 & 0.4 & 0.7 \\
\hline 0.4 & 0.4 & 0.4 & 0.4 & 0.6 & 0.5 & 0.3 & 1. & 0.3 & 0.2 & 0.4 & 0.7 & 0. & 0.4 & 4 & 3 & 0.5 & 0.5 & 0.5 & 0.7 & 0.5 & 0.6 & 0.7 & 0.6 & 0.6 & 0.3 & 0.0 & 0.7 & 0.9 \\
\hline 0.9 & 0.9 & 0.9 & 0.9 & 1.2 & 1. & 0.3 & 1.7 & 0.6 & 0.7 & 1.2 & 0 & 0.7 & 0.7 & 0.7 & 0.4 & 0.9 & 0.9 & 0.8 & 1.0 & 0.5 & 1.2 & 1.2 & 1.1 & 1.1 & 0.4 & 0.7 & 0.0 & 0.5 \\
\hline 1.2 & 1.2 & 1.2 & 1.1 & 1.4 & 1.3 & 0.5 & 1.8 & 0.9 & 1.0 & 0.6 & 1.2 & 0.9 & 1.1 & 1.1 & 0.6 & 1.2 & 1.2 & 1.2 & 1.2 & 0.6 & 1.4 & 1.4 & 1.4 & 1.3 & 0.7 & 0.9 & 0.5 & 0.0 \\
\hline & & & & & & & & & & & & & & & & & & & & & & & & & & & & \\
\hline & & & & & 0 & & & 0.3 & & & 0.4 & & & 0.5 & & & 0.6 & & & 0.1 & & & .0 & & & & & \\
\hline
\end{tabular}




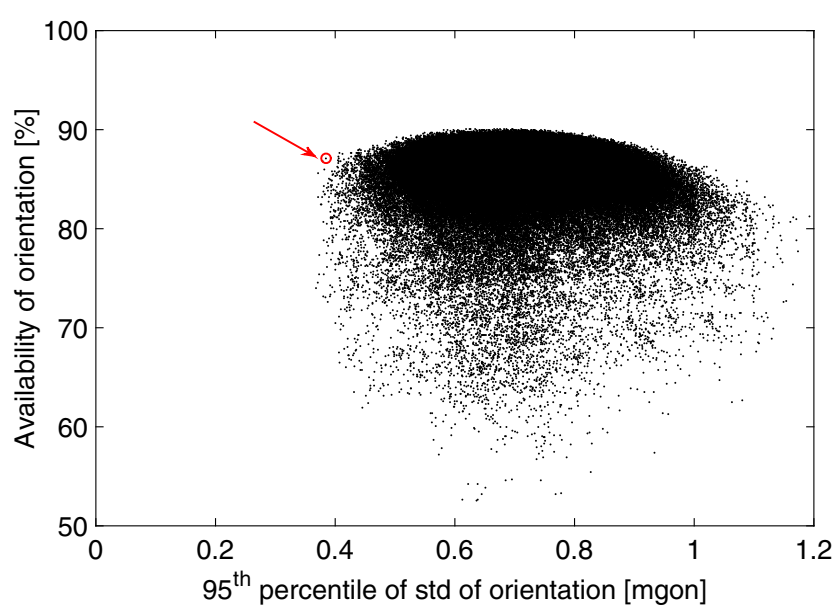

Fig. 17 Availability and 95th percentile of standard deviation of orientation for all candidate sets of orientation points based on data from 15 March 2014 to 3 August 2014; selected optimum candidate indicated by an arrow

considered available if it could be computed from at least five target points (outliers again removed using median and MAD, but only within the respective epoch). The precision was measured by calculating the empirical standard deviation and that of the estimated (mean) orientation within each epoch and finally selecting the 95 th percentile of the standard deviations of the estimated orientations.

The result is displayed in Fig. 17. Obviously, there is a trade-off between high availability and low standard deviation, and a further criterion is needed to retrieve an optimum set of points based on this multi-objective optimization. We selected the set whose quality is indicated by the arrow in Fig. 17; it corresponds to points $\{1,2,3,4,9,10,13,17$, 27 with an orientation availability of $87 \%$ and standard deviation of the orientation better than 0.38 mgon in $95 \%$ of the cases. As the figure shows, (slightly) higher availability is only achievable at the cost of (much) higher standard deviation while (slightly) lower standard deviation is only achievable at the cost of (much) lower availability; the chosen solution is an inflection point on the Pareto front and therefore optimum (see, e.g., Domingo-Perez et al. 2016). ${ }^{6}$

Using Fig. 14, we see that the set of orientation points identified using the above algorithm comprises mostly the points located within the same profile as RTS1 and two more points located on the same side of the valley as RTS1 and thus subject to almost the same displacements as far as narrowing and widening of the valley is concerned. So, it is plausible that this choice is useful to establish a stable orientation reference; furthermore - based on the above analysis - it is also clear that it does so with high availability. Figure 18 shows the horizontal angles of a point (10) after application of the

\footnotetext{
$\overline{6}$ The same optimum solution has also been found with much less computational effort by starting from the subset of 18 candidate points, iteratively removing the one contributing most to the empirical standard deviation of the orientations, and stopping once there were only 9 points left.
}

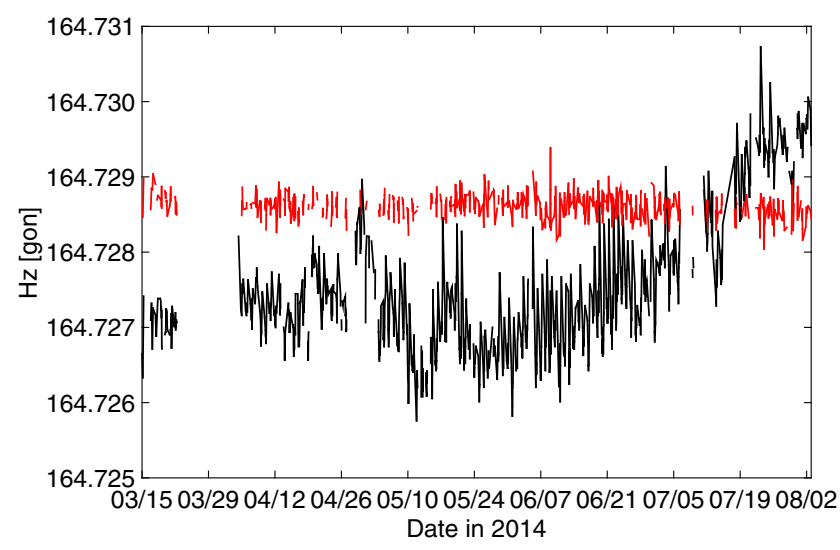

Fig. 18 Time series of horizontal angles of point 10 before (black) and after (red) application of the orientation calculated from the above orientation points

orientation calculated from the above subset of points. The result is representative for all points. It shows that short- and long-term variations of the horizontal angle are successfully mitigated. The remaining noise is fully explained by the standard deviation of the angle measurements. A corresponding study for RTS2 is yet to be carried out.

\section{Conclusion}

We have analyzed various systematic effects deteriorating estimated displacements calculated from robotic total station (RTS) measurements in an alpine environment.

We showed why an additional housing of a RTS with windows should be avoided if possible; partial obstruction of the field-of-view and reflections from the windows may go unnoticed by the instrument and may cause deviations exceeding the instrument specifications by 1-2 orders of magnitude. If housing is necessary, holes larger than the aperture of the telescope should be drilled and the measurements should be taken through these holes.

The solid rock supporting the pillar of one of the RTS was found to have diurnal tilt variations on the level of 3 mgon which might cause significant total station displacement. Further displacements due to potential bending of the pillar (horizontal temperature gradients up to $1 \mathrm{~K}$ were found within the double-layer pillar) or tilting of the pillar and instrument were found to be on the level of $0.2 \mathrm{~mm}$ or less and thus usually negligible. For nearby targets, the temperatureinduced pillar height variations of up to about $1 \mathrm{~mm}$ might have to be taken into account using numeric eccentricity corrections.

Vertical angle variations up to about 1 mgon for lines-ofsight (LoS) of about $1 \mathrm{~km}$ were predicted due to vertical refraction across the valley and up to about 3 mgon for LoS along the valley using a simplified model based on actual meteo observations. It corresponded well to the actual 
variations of the measurements in terms of order of magnitude and temporal variability. Correlated short-term distance variations of 2-4 ppm were found for all LoS across and along the valley suggesting that it may be possible to reduce them using a time-dependent scaling factor.

Using a multi-objective optimization approach, a set of points was identified for determination of the total station orientation. The horizontal angles measured to these points are mostly unaffected by annual widening and narrowing of the valley, such that this orientation may be combined with GNSS-derived position updates of the RTS sites in order to establish a suitable geodetic datum for deformation analysis.

Future extensions of the network should include prisms collocated with GNSS antennas in order to (i) support datum definition and (ii) possibly provide reference distances for local scale factor estimation despite the annual deformation signals.

Acknowledgements The authors thank Simon Löw, Franziska Glüer, Reto Seifert, and Lorenz Grämiger from the Engineering Geology Group, ETH Zürich, for granting access to data from various sensors installed and operated by them and for the cooperation during field trips.

Open Access This article is distributed under the terms of the Creative Commons Attribution 4.0 International License (http:// creativecommons.org/licenses/by/4.0/), which permits unrestricted use, distribution, and reproduction in any medium, provided you give appropriate credit to the original author(s) and the source, provide a link to the Creative Commons license, and indicate if changes were made.

\section{References}

Brocks K (1948) Über den täglichen und jährlichen Gang der Höhenabhängigkeit der Temperatur in den unteren 300 Metern der Atmosphäre und ihren Zusammenhang mit der Konvektion. Berichte des Deutschen Wetterdienstes in der US-Zone, Nr. 5 (in German)

Brunner FK (1982) The effects of atmospheric turbulence on telescopic observations. Bulletin Géodésique 56:341-355

Caduff R, Schlunegger F, Kos A, Wiesmann A (2015) A review of terrestrial radar interferometry for measuring surface change in the geosciences. Earth Surf Process Landf 40:208-228

Charalampos E, Psimoulis P, Guillaume S, Spiridonakos M, Klis R, Bürkli B, Rothacher M, Chatzi E, Luchsinger R, Feltrin G (2015) Measuring sub-mm structural displacements using QDaedalus: a digital clip-on measuring system developed for total stations. Applied Geomatics 7:91-101
Ciddor PE (1996) Refractive index of air: new equations for the visible and near infrared. Appl Opt 35:1566-1573

Ciddor PE, Hill RJ (1999) Refractive index of air. Appl Opt 38:16631667

Crosta GB, Agliardi F (2003) Failure forecast for large rock slides by surface displacement measurements. Can Geotech J 40:176-191

Di Crescenzo G, Santo A (2007) High-resolution mapping of rock fall instability through the integration of photogrammetric, geomorphological and engineering-geological surveys. Quat Int 171-172:118 130

Domingo-Perez F, Lazaro-Galilea JL, Wieser A, Martin-Gorostiza E, Salido-Monzu D, de la Llana A (2016) Sensor placement determination for range-difference positioning using evolutionary multiobjective optimization. Expert Syst Appl 47:95-105

Gigli G, Morelli S, Fornera S, Casagli N (2014) Terrestrial laser scanner and geomechanical surveys for the rapid evaluation of rock fall susceptibility scenarios. Landslides 11:1-14

Glueer F, Loew S, Seifert R, Frukacz M, Wieser A (2015) Design and operation of a comprehensive and permanent rock slope deformation monitoring system at the Great Aletsch Glacier (Switzerland). Geophysical Research Abstracts, Vol. 17, EGU General Assembly 2015

Kaalberg FJ, Braakman S, Cook DK (2003) Amsterdam Noord/Zuidlijn: one of the largest settlement monitoring projects in Europe. In: Proc. of the 6th international symposium on field measurements in geomechanics, Oslo: 769-774

Langbein J, Johnson H (1997) Correlated errors in geodetic time series: implications for time-dependent deformation. J Geophys Res 102: 591-603

Loew S, Gitschig V, Moore JR, Keller-Signer A (2012) Monitoring of potentially catastrophic rockslides. In: Eberhardt E, Froese C, Turner K, Leroueil S (eds) Landslides and engineered slopes: protecting society through improved understanding. Taylor \& Francis Group, London, pp 101-116

Niemeier W (1985) Deformationsanalyse. In: Pelzer H (ed) Geodätische Netze in Landes- und Ingenieurvermessung II. Konrad Wittwer, Stuttgart, pp 559-623 (in German)

Papastamos G, Stiros SC, Saltogianni V, Kontogianni VA (2015) 3-D strong tilting observed in tall, isolated brick chimneys during the excavation of the Athens Metro. Applied Geomatics 7:115-121

Pytharouli SI, Kontogianni VA, Stiros SC (2007) Kinematics of two deep-seated landslides in Greece. Geotechnical Engineering Journal (ICE) 160:179-183

Rolland C (2003) Spatial and seasonal variations of air temperature lapse rates in alpine regions. J Clim 16:1032-1046

Soni A, Robson S, Gleeson B (2015) Structural monitoring for the rail industry using conventional survey, laser scanning and photogrammetry. Applied Geomatics 7:123-138

Stiros SC, Vichas C, Skourtis C (2004) Landslide monitoring based on geodetically derived distance changes. J Surv Eng 130:156-162

Van der Broeke MR (1997) Structure and diurnal variation of the atmospheric boundary layer over a mid-latitude glacier in summer. Bound-Layer Meteorol 83:183-205 